\title{
Research on the Sustainable Economy Development Mode of Automobile Parts Companies Based on Reverse Logistics
}

\author{
Suchun $\mathrm{FANG}^{1}{ }^{1}$, Yang $\mathrm{FANG}^{2}$, Huimin $\mathrm{SuN}^{2}$, and Yan $\mathrm{YU}^{2}$ \\ ${ }^{1}$ Department of Human Studies, Seisen University, 720 Hida-cho, Hikone, Shiga Prefecture, Japan \\ ${ }^{2}$ School of Economics, Changchun University, 6543 Weixing Road, Changchun, China
}

\begin{abstract}
Problems such as resource shortage and environment deterioration are serious problem now. Therefore, developing sustainable economy becomes an inescapable choice in global economy. As an important activity, developing sustainable economy, the economic and social value of reverse logistics, has emerged now. This paper focus on the recycle of spare parts obtained from the end of life (here after EOL) automobile, which can replace disabled parts of an automobile. We argue that developing the reverse logistics of automobile spare parts (here after the "replenishment parts") is an important measure to sustainable economy, either local or national or global economy. Recent year, Chinese government is promoting reverse logistic activities, however, not yet introduced regulations and established a management system for the reverse logistics system of automobile spare parts. Considering China's automobile replacement parts industry mode, the authors attempts to propose a management system for the replenishment parts recycle so that the production, delivery, utilization, recycle and repair become a concrete closed loop supply chain. This system not only conforms to the Extended Producer Responsibility (ERP) policy push forward by the government to the automobile manufacturers, but also can integrate active involvement of major players of Chinese automobile industry.
\end{abstract}

Key Words : Reverse logistics, Automobile replacement parts, Sustainable economy, Recycle system

\section{Reverse logistics and sustainable economy}

With the great potential of economic growth, the pressure of resource shortage and the increase of various rejected material have been rising substantially. Since the 1990s, developed countries have paid attention to reverse logistics and many enterprises have it so that to enhance their competing power from cost and social evaluation. Automobile industry is one which consumes more resource and brings more pollution. As the operating automobiles are increasing in the world, the number of disabled automobiles is also increasing now. If the disabled automobiles can't be recycled timely and efficiently, more natural resource will be introduced into the automobile industry therefore the world will be more polluted and less sustainable. As one of the automobile markets with most potentialities, China is faced with serious problems of resource scarcity and environmental pollution, for example the PM2.5 air pollution. In order to save natural resource and contribute to the sustainable economy, it is important to analyse reverse logistics system and introduce it to China's automobile industry.

Reverse logistics was initially included in the research report presented by Stock to Council of Logistics Management (CLM) in 1992. In the report, the reverse logistics is defined as a logistics activity, in which the procedure included return of products, material substitution, goods reuse, scrap treatment and retreatment, maintenance and reproduce. From the defini-

Corresponding Author: Yan Yu

School of Economics, Changchun University, 6543 Weixing

Road, Changchun, 130022 China

yuyanchina2005@126.com

(Received March 14, 2013)

(Revised May 15, 2013)

(Accepted May 29, 2013) tion we can see that reverse logistics contains all the activities included in the forward logistics except the direction of the material move. Reverse logistics is the opposite transfer of goods among channel members that is the flow from the place of destination to the place of departure. Forward and reverse logistics constitutes a closed-loop supply chain management (CLSCM). The goods recycling and reuse in the course makes enterprises run more effectively.

Sustainable economy changes the single flow of "resource $\rightarrow$ products $\rightarrow$ utilize $\rightarrow$ scrap and pollution" in traditional economy into a closed loop that shapes "resource $\rightarrow$ products $\rightarrow$ utilize $\rightarrow$ recycle and reuse $\rightarrow$ products" flow. With respect to the definition of reverse logistics, we can see that reverse logistics is helpful to reduce resource waste and the pollution hence to prevent pollution and save nature resources. Meanwhile, it can reduce the cost of disposing of rejected material and improve the efficiency of the enterprise and the whole supply chain and realize social and economical benefit. The reverse logistics is the significant part of resource circulation and create value continuously which we call the circular economy in this paper. This circular economy requires revers logistics for companies as well as the nation-wide reverse logistic system.

\section{Reverse logistics of automobile replacement parts}

The reverse logistics of automobile repair parts is to regain the use value of disabled parts and renew resources and finally to dispose the disabled material properly. There are both recycling logistics and logistics of disabled material, including recalling unqualified products, recapping the old repair parts from the abandoned automobiles, classifying, maintaining and remaking the damaged parts or returning them to the automobile assembly or repair parts suppliers. 
In China, the motorization begun a decade ago and those automobiles purchased before 10-15years now became end of life (EOL) product. Chinese government pays great importance to the scrapping of automobiles and engaged in the car disassembles and recycles of the EOL automobiles as measures of saving natural resources and contribute to the circular economy. This effort unavoidably produces large quantities of disabled automobile repair parts which will be an important part of reverse logistics.

\section{Recycle system of EOL automobiles}

\subsection{The recycling of EOL automobiles and automobile in- dustry}

The recycling and reuse of EOL automobiles are the extension of the supply chain of automobile industry, and also essential parts to improve efficiency of the whole automobile industry. The recycling and reuse of EOL automobiles forms CLSCM together with the forward supply chain. On the one hand, the available material from the EOL automobiles can be reused in the manufacturing and maintenance of automobiles, while the renewal of EOL automobiles can contribute to the consumption and manufacturing of automobiles. In 2010, the number of EOL automobiles was about 450,000 units and will be doubled in 2020. As the automobile product is more complicated mechanically and electrically, the recycle and reuse of EOL automobiles are more difficult than other products.

\subsection{The recycling method of EOL automobiles}

Automobile is assembled with various mechanical component and electronic components, and these components are made by different material which should be separated with reasonable methods, and then to be disposed or reused separately. We would be able to improve the recycling and reuse of EOL automobiles, by improving disassembling technology of EOL automobiles. This is also an important approach to save resources and establish circular economy.

As for the problems in the recycling of EOL automobiles, appropriate recycling system may be built according to the countermeasures of implementing reverse logistics of automobile repair parts presented in the above. Considering all the parties involved in the recycling system, including raw material suppliers, automobile manufacturers, recycling enterprises, dismantling enterprises and professional maintaining or material disposal firms, and combining with the recycling policies and the present situation, the author proposes the recycling method of EOL automobiles.

\section{Index system and evaluation model of reverse logis- tics system of automobile parts}

\subsection{The establishment of index system}

The authors make qualitative analysis about the environmental impact of automobile reverse logistics, and combining with quantitative approach evaluates the reverse logistics system of automobile repair parts. According to the characteristics of automobile reverse logistics, we propose two-layer index evaluation system, in which each factor can be separated to the three or more sub factors. We analyse the main factors influencing the logistics system in order to determine the evaluation contents and index, and then we evaluate the reverse logistics system. Combining with the characteristics of reverse logistics of automobile parts, the author constructed a new evaluation system.

\subsection{The fuzzy analytic hierarchy process}

Considering the analytic hierarchy process with the advantages of systematic and flexible, and the fuzzy evaluation with advantage to analyze fuzziness and uncertainty, this paper combined the two methods, adopting the fuzzy analytic hierarchy process as evaluation method, on the basis of index analysis establishing hierarchical structure and determining the index weighting.

\subsection{The analytic hierarchy process}

The analytic hierarchy process (AHP) separates problems into different elements according to the characteristics of these problems thus forms a hierarchical structure model; then grades each element in each hierarchy according to their pairwise judgment importance and builds judgment matrix; determines the weighting of all indices in each hierarchy with mathematical technique; finally, through integrated calculation gets the combination weight of the lowest hierarchy compared with the highest hierarchy, which could be as the basis of evaluation.

\subsection{The fuzzy comprehensive evaluation method}

The fuzzy comprehensive evaluation method is a very effective way of multi-element decision to overall evaluate matters affected by various elements. Its characteristic is that the evaluation result is not absolutely positive or negative but represented by a fuzzy set.

1. Suppose an element set $U=\left\{u_{1}, u_{2}, \cdots u_{n}\right\}$ is the index evaluation system

2. Suppose an evaluation set $V=\left\{v_{1}, v_{2}, \cdots, v_{n}\right\}$ and $v_{1}$ is the best, $v_{2}$ is good, $v_{3}$ is average, $v_{4}$ is inferior.

3. To establish fuzzy relation matrix $R$, that is each element of $u$ in $U$, the subordination relationship of $v_{i}$ in the corresponding $V$;

iv According to the given weight $A$, choosing appropriate composition operator and combining $A$ and $R$, we can get the result of the fuzzy comprehensive evaluation $B$;

4. To make a fuzzy comprehensive analysis of $B$ and get the evaluation result of the evaluation object.

\section{The empirical analysis on reverse logistics of auto- mobile parts}

The author made interview to 8 professors in the area about each evaluation index in the relative index system of the automobile repair parts. Because the index evaluation system is multi-layered, when we calculate the relative importance of the indices of each layer to the upper layer, we calculate the index weight from the higher hierarchy to the lower one.

\subsection{The determination of the primary index weighting}

As for the relative importance of resource nature, economical nature, environmental nature, technology nature and social nature of the indices in the first layer, the author referred to 1-9 scale method. Using the evaluation data from the professors, 


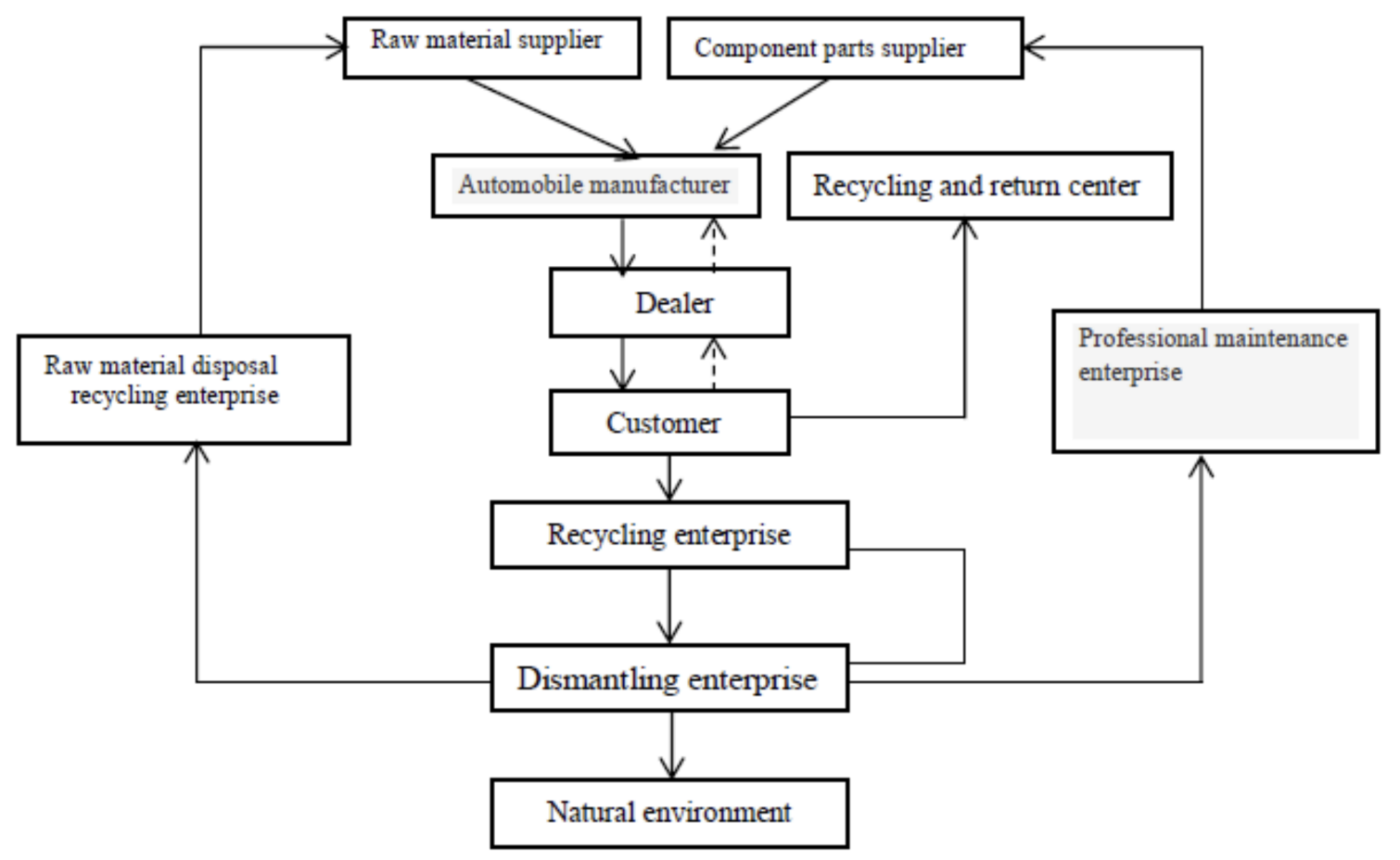

Fig. 1 Recycling method of scrapped automobiles

Table 1 Calculation form of the first level index weighting

\begin{tabular}{|l|c|c|c|c|c|c|c|c|}
\hline $\mathrm{A}-\mathrm{U}$ & $U_{1}$ & $U_{2}$ & $U_{3}$ & $U_{4}$ & $U_{5}$ & Product & $5^{\text {th }}$ Power root & Normalization W \\
\hline$U_{1}$ & 1 & 5 & 2 & 4 & 6 & 240.0 & 2.992 & 0.4304 \\
\hline$U_{2}$ & $1 / 5$ & 1 & $1 / 5$ & 2 & 4 & 0.32 & 0.796 & 0.1145 \\
\hline$U_{3}$ & $1 / 2$ & 5 & 1 & 4 & 6 & 60.0 & 2.267 & 0.3261 \\
\hline$U_{4}$ & $1 / 4$ & $1 / 2$ & $1 / 4$ & 1 & 2 & 0.0625 & 0.574 & 0.0826 \\
\hline$U_{5}$ & $1 / 6$ & $1 / 4$ & $1 / 6$ & $1 / 2$ & 1 & 0.0035 & 0.322 & 0.0464 \\
\hline
\end{tabular}

the author got the judgment matrix. Then according to the calculating method of the hierarchical analysis, we calculate the weighting of each index.

From 1, we can get the feature vector of the primary index : $W=(0.4304,0.1145,0.3261,0.0826)$. And calculate the maximum feature vector

$$
\begin{aligned}
& \lambda_{\text {max }}=\sum_{i=1}^{n} \frac{B \cdot W_{1}}{n \cdot W_{1}}=5.0364, \\
& C I=\frac{\lambda_{\text {max }}-n}{N-1}=0.091
\end{aligned}
$$

where $B$ is matrix of fuzzy comprehensive evaluation.

Giving $R I=1.12$, we get

$$
C R=\frac{C I}{R I}=0.081 \leq 0.1
$$

Therefore, we can conclude that the judgment has satisfying consistency.

\subsection{To determine the weighting of secondary}

Referring to the determination method of primary index weighting, we can determine the weighting of the secondary indices in the evaluation index system.

\subsection{To establish evaluation set}

There are four grades when establishing evaluation set; very good, good, average and bad respectively. The experts evaluate the operation performance of the enterprise 's reverse logistics and determine the membership degree of each index according to the operation performance of each index in the indices evaluation system of reverse logistics of the automobile parts enterprises and the relative stipulation of each index in China and the actual operation situation in the enterprises.

\subsection{To exercise fuzzy evaluation}

We can get the relationship matrix of each element according to the evaluation matrix of membership degree in Table 3. We name them $A_{1}, A_{2}, A_{3}, A_{4}, A_{5}$ respectively. The following form (Table 4) explaining the combination weighting of the secondary indices could be concluded according to the two-layer index weighting obtained through analytic hierarchical process in part 1 and part 2 of this section.

\subsection{The comprehensive evaluation matrix of single ele- ment}

The comprehensive evaluation of the element $\mathrm{J}$ in group I could be represented as:

$$
\begin{aligned}
& B=A \cdot R=\left(a_{1}, a_{2}, \ldots, a_{p}\right)\left(\begin{array}{cccc}
r_{11} & r_{22} & \ldots & r_{1 n} \\
r_{21} & r_{22} & \ldots & r_{2 n} \\
\ldots & \ldots & \ldots & \ldots \\
r_{p 1} & r_{p 2} & \ldots & r_{p n}
\end{array}\right) \\
& B=\left(b_{1}, b_{2}, \ldots, b_{j}, \ldots, b_{n}\right)
\end{aligned}
$$


Table 2 Evaluation index weighting form

\begin{tabular}{|c|c|c|c|c|}
\hline $\begin{array}{l}\text { Order } \\
\text { Number }\end{array}$ & Primary indices & Weighting & Secondary indices & Weighting \\
\hline \multirow{5}{*}{1} & \multirow{5}{*}{ Environmental nature $U_{1}$} & \multirow{5}{*}{0.4304} & $U_{11}$ water pollution index & 0.106416 \\
\hline & & & $U_{12}$ air pollution index & 0.073638 \\
\hline & & & $U_{13}$ pollution index of solid disabled goods & 0.506803 \\
\hline & & & $U_{14}$ noise pollution & 0.042363 \\
\hline & & & $U_{15}$ disabled liquid pollution & 0.270779 \\
\hline \multirow{3}{*}{2} & \multirow{3}{*}{$\begin{array}{l}\text { Economical } \\
\text { nature } U_{2}\end{array}$} & \multirow{3}{*}{0.1145} & $U_{21}$ enterprise cost & 0.077931 \\
\hline & & & $U_{22}$ customer cost & 0.287209 \\
\hline & & & $U_{23}$ ecological environment cost & 0.634859 \\
\hline \multirow{5}{*}{3} & \multirow{5}{*}{$\begin{array}{l}\text { Resource } \\
\text { nature } U_{3}\end{array}$} & \multirow{5}{*}{0.3261} & $U_{31}$ resource elimination of unit product & 0.106136 \\
\hline & & & $U_{32}$ green energy ratio & 0.045190 \\
\hline & & & $U_{33}$ utilization rate of recycling material & 0.496925 \\
\hline & & & $U_{34}$ recycling rate of packing or container & 0.124513 \\
\hline & & & $U_{35}$ recycling rate of products & 0.227237 \\
\hline \multirow{3}{*}{4} & \multirow{3}{*}{$\begin{array}{l}\text { Technical } \\
\text { nature } U_{4}\end{array}$} & \multirow{3}{*}{0.0826} & $U_{41}$ management information level & 0.581547 \\
\hline & & & $\begin{array}{l}U_{42} \text { level of use of environmental } \\
\text { protection equipment }\end{array}$ & 0.308994 \\
\hline & & & $U_{43}$ level of operation of green process & 0.109459 \\
\hline \multirow{4}{*}{5} & \multirow{4}{*}{ Social nature $U_{5}$} & \multirow{4}{*}{0.0464} & $U_{51}$ supply chain member support & 0.446673 \\
\hline & & & $U_{52}$ social ethics and culture impact & 0.060942 \\
\hline & & & $\begin{array}{l}U_{53} \text { level of perceived value to } \\
\text { the consumer }\end{array}$ & 0.137153 \\
\hline & & & $U_{54}$ relative environment benefit & 0.355232 \\
\hline
\end{tabular}

Table 3 Membership degree form of evaluation indices

\begin{tabular}{|c|c|c|c|c|c|c|}
\hline $\begin{array}{c}\text { Order } \\
\text { Number }\end{array}$ & Primary indices & Secondary indices & $\begin{array}{l}\text { Very } \\
\text { Good }\end{array}$ & Good & Average & Bad \\
\hline \multirow{5}{*}{1} & \multirow{5}{*}{ Environmental nature $U_{1}$} & $U_{11}$ water pollution index & 0.500 & 0.250 & 0.250 & 0.000 \\
\hline & & $U_{12}$ air pollution index & 0.250 & 0.500 & 0.125 & 0.125 \\
\hline & & $U_{13}$ pollution index of solid disabled goods & 0.500 & 0.375 & 0.125 & 0.000 \\
\hline & & $U_{14}$ noise pollution & 0.250 & 0.375 & 0.125 & 0.250 \\
\hline & & $U_{15}$ disabled liquid pollution & 0.125 & 0.375 & 0.375 & 0.125 \\
\hline \multirow{3}{*}{2} & \multirow{3}{*}{$\begin{array}{l}\text { Economical } \\
\text { nature } U_{2}\end{array}$} & $U_{21}$ enterprise cost & 0.625 & 0.250 & 0.125 & 0.000 \\
\hline & & $U_{22}$ customer cost & 0.500 & 0.375 & 0.125 & 0.000 \\
\hline & & $U_{23}$ ecological environment cost & 0.375 & 0.375 & 0.125 & 0.125 \\
\hline \multirow{5}{*}{3} & \multirow{5}{*}{$\begin{array}{l}\text { Resource } \\
\text { nature } U_{3}\end{array}$} & $U_{31}$ resource elimination of unit product & 0.375 & 0.250 & 0.250 & 0.250 \\
\hline & & $U_{32}$ green energy ratio & 0.250 & 0.250 & 0.250 & 0.250 \\
\hline & & $U_{33}$ utilization rate of recycling material & 0.250 & 0.375 & 0.125 & 0.250 \\
\hline & & $U_{34}$ recycling rate of packing or container & 0.375 & 0.250 & 0.250 & 0.125 \\
\hline & & $U_{35}$ recycling rate of products & 0.375 & 0.375 & 0.125 & 0.125 \\
\hline \multirow{3}{*}{4} & \multirow{3}{*}{$\begin{array}{l}\text { Technical } \\
\text { nature } U_{4}\end{array}$} & $U_{41}$ management information level & 0.625 & 0.250 & 0.125 & 0.000 \\
\hline & & $\begin{array}{l}U_{42} \text { level of use of environmental } \\
\text { protection equipment }\end{array}$ & 0.500 & 0.500 & 0.000 & 0.000 \\
\hline & & $U_{43}$ level of operation of green process & 0.375 & 0.375 & 0.125 & 0.125 \\
\hline \multirow{4}{*}{5} & \multirow{4}{*}{ Social nature $U_{5}$} & $U_{51}$ supply chain member support & 0.250 & 0.250 & 0.375 & 0.125 \\
\hline & & $U_{52}$ social ethics and culture impact & 0.500 & 0.250 & 0.250 & 0.125 \\
\hline & & $\begin{array}{l}U_{53} \text { level of perceived value to } \\
\text { the consumer }\end{array}$ & 0.500 & 0.375 & 0.125 & 0.000 \\
\hline & & $U_{54}$ relative environment benefit & 0.375 & 0.375 & 0.125 & 0.125 \\
\hline
\end{tabular}

$$
B_{1}=A_{1} R_{1}=0.159637
$$

It can be seen from the above calculation that the evaluation grade of the resource nature is good according to the maximum membership degree, the score of which is 0.159637 .

From the above formula we can get the evaluation situation of other natures one by one.

$$
\begin{aligned}
& B_{2}=A_{2} R_{2}=0.049279, \quad B_{3}=A_{3} R_{3}=0.111044 \\
& B_{4}=A_{4} R_{4}=0.046174, \quad B_{5}=A_{5} R_{5}=0.015958
\end{aligned}
$$

From the evaluation situation of each nature in the above and according to the score of each nature we can build the relation- ship matrix of the whole reverse logistics system of the manufacturing enterprise.

$$
R=\left\{\begin{array}{cccc}
0.159015 & 0.159637 & 0.088661 & 0.02308 \\
0.049279 & 0.041822 & 0.014313 & 0.00908 \\
0.10019 & 0.111044 & 0.052006 & 0.06286 \\
0.046174 & 0.029291 & 0.007135 & 0.00000 \\
0.015958 & 0.014456 & 0.011335 & 0.00465
\end{array}\right\}
$$

The comprehensive evaluation of the reverse logistics system is:

$$
B=A \times R=(80.111309,0.112798,0.057873,0.031692)(8)
$$


Table 4 Combination weighting of the secondary indices

\begin{tabular}{|c|c|c|c|}
\hline $\begin{array}{c}\text { Order } \\
\text { Number }\end{array}$ & Primary indices & Secondary indices & Secondary indices \\
\hline \multirow{5}{*}{1} & \multirow{5}{*}{ Environmental nature $U_{1}$} & $U_{11}$ water pollution index & 0.045801 \\
\hline & & $U_{12}$ air pollution index & 0.031694 \\
\hline & & $U_{13}$ pollution index of solid disabled goods & 0.218128 \\
\hline & & $U_{14}$ noise pollution & 0.018233 \\
\hline & & $U_{15}$ disabled liquid pollution & 0.116543 \\
\hline \multirow{3}{*}{2} & \multirow{3}{*}{$\begin{array}{l}\text { Economical } \\
\text { nature } U_{2}\end{array}$} & $U_{21}$ enterprise cost & 0.008923 \\
\hline & & $U_{22}$ customer cost & 0.032885 \\
\hline & & $U_{23}$ ecological environment cost & 0.072691 \\
\hline \multirow{5}{*}{3} & \multirow{5}{*}{$\begin{array}{l}\text { Resource } \\
\text { nature } U_{3}\end{array}$} & $U_{31}$ resource elimination of unit product & 0.034611 \\
\hline & & $U_{32}$ green energy ratio & 0.014736 \\
\hline & & $U_{33}$ utilization rate of recycling material & 0.162047 \\
\hline & & $U_{34}$ recycling rate of packing or container & 0.040604 \\
\hline & & $U_{35}$ recycling rate of products & 0.074102 \\
\hline \multirow{3}{*}{4} & \multirow{3}{*}{$\begin{array}{l}\text { Technical } \\
\text { nature } U_{4}\end{array}$} & $U_{41}$ management information level & 0.048036 \\
\hline & & $\begin{array}{l}U_{42} \text { level of use of environmental } \\
\text { protection equipment }\end{array}$ & 0.025523 \\
\hline & & $U_{43}$ level of operation of green process & 0.009041 \\
\hline \multirow{4}{*}{5} & \multirow{4}{*}{ Social nature $U_{5}$} & $U_{51}$ supply chain member support & 0.020726 \\
\hline & & $U_{52}$ social ethics and culture impact & 0.002828 \\
\hline & & $\begin{array}{l}U_{53} \text { level of perceived value to } \\
\text { the consumer }\end{array}$ & 0.006364 \\
\hline & & $U_{54}$ relative environment benefit & 0.016483 \\
\hline
\end{tabular}

It can be seen from the above analysis that in the evaluation system of the reverse logistics system of this enterprise the scores of resource nature and environmental nature are lower. These two items include more indexes and the domestic automobile parts enterprises didn 稚 pay enough attention to the resource and environmental nature. If the automobile parts enterprises wish to improve the performance of the reverse logistics system, they must enhance the concerning indexes in these two natures.

\section{Conclusions}

As an important part of the national economy, the automobile and automobile parts manufacturer should pay much more attention to the negative influence to the environment brought by the enterprise behavior and try to minimize the negative influence. We can see from the operation situation of reverse logistics of the automobile parts manufacturer that more and more enterprises have attached importance to the indices in the index evaluation system, especially those which have greater influence on the resource and environment. Those indices include the use rate of the recycling material, recycling rate of products, the pollution of solid disabled goods and disabled liquid pollution, etcetera. The above research conforms to the interest of the automobile parts enterprises, which verifies the creditability of the index evaluation system.

\section{References}

[1] C. Cater and L. Ellram,1998, Reverse Logistics: A Review of the Literature and Framework for Future Investigation, Journal of Business Logistics, 1(1), 120-128.

[2] Yu Yan, Sun Huimin, 2009, Research on the Choice of Logistics Distribution Center Based on the Scale Economy Theory, 2009 Second International Conference on Intelligent Computation Technology and Automation (IEEE ICICTA 2009), 980983.

[3] Ou Zhongwen, Chen Guoxu, Zhang Yunhuai, Xu Binshi, Chen Peng, 2005,Study on Industrialization Integration Be- tween Waste Logistic and Remanufacture of Motor Vehicle of Chongqing, Journal of Chongqing University (Natural Science Edition), 28(12), 134-137.

[4] Yu Yan,2009, Grey Relational Evaluation of the International Competitive Ability for Automobile Repair parts Industry, Social Science Front, 9(8), 105-107.

[5] Pan Fulin, Xu Chunyan, 2009,Study on Development of China' s Automobile Remanufacturing Industry, Economic daily press, 9(6), 45-50.

[6] Zhang Kang, Su Chun, Xu Yingqiu,2006, Evaluation of the Recovery of Automobile Materials Based on Fuzzy Analytic Hierarchy Process , Industrial Engineering Journal, 9 (4), 4446.

[7] Wu Dan, Lin Yun, Dai Ying, 2007,Architectural Framework about Recycle of Waste Automobile , Logistics Scitech, 29(9), 155-158.

|

\section{Suchung FANG}

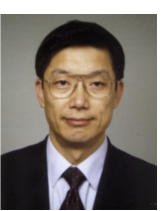

is a professor at Seisen University. He received his $\mathrm{PhD}$ degree from Kyoto University, Kyoto, Japan, in 1993.His main research interests include business administration and management engineering. For recent 5 years, he has published 16 papers and two books.

\section{Yang FANG}

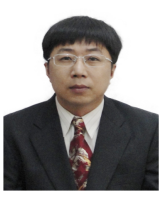

is a lecturer of school of Economics Changchun Univerisity. He received the B.S, M.S, and Ph.D.degrees from Changchun University of Technology, Kyoto Prefectural University and Shiga Prefecture University, in 1997,2003 and 2007 ,respectively. He has been researching in the fields of policy on the development of Alternative Fuel Vehicle and the theory of business management. For recent 5 years, he has published more than 10 papers and one book. 


\section{Hui-Min Sun}

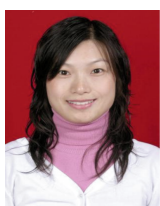

is a teacher of Changchun University, she received a B.S. degree from Jilin Finance University and a M.S. degree from Jilin University in 2003 and 2006 respectively. Her research focuses on the fields of the application of industrial economics theories and relationship between regional economy and regional logistics.

\section{Yan $Y_{U}$}

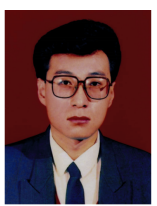

is a professor of Changchun University, he received a M.S. degree of Production system engineering from Nagoya Institute of Technology in the year of 2000 and Ph.D. degree of Technical economy and management from Jilin University in 2008. His research exists in the fields of efficiency evaluation of industry innovation system and application of reverse logistics theories. He has published 42 papers and 1 book. 